\title{
Effects of a home-based exercise program after supervised resistance training in patients with chronic obstructive pulmonary disease
}

\author{
Efeitos de um programa domiciliar de exercícios após um treinamento resistido \\ supervisionado em pacientes com doença pulmonar obstrutiva crônica
}

Giovana N. Bertolini ${ }^{1}$, Dionei Ramos ${ }^{2}$, Marceli R. Leite ${ }^{1}$, Luiz Carlos Soares de Carvalho Junior ${ }^{1}$, Ana Paula C. F. Freire ${ }^{1}$, Fabiano Francisco de Lima ${ }^{1}$, Bruna Spolador de Alencar Silva ${ }^{1}$, Carlos Marcelo Pastre ${ }^{2}$, Ercy Mara C. Ramos ${ }^{2}$

\begin{abstract}
RESUMO
Desenho do estudo: ensaio clínico. Objetivo: Avaliar os efeitos de um programa de exercícios resistidos em domicílio, com tubos elásticos, após o treinamento resistido supervisionado sobre a força muscular periférica e qualidade de vida de pacientes com doença pulmonar obstrutiva crônica (DPOC). Métodos: O estudo incluiu 22 pacientes com DPOC, com idade entre 55-70 anos. A força muscular periférica e a qualidade de vida foram avaliados por meio da dinamometria e do questionário Chronic Respiratory Questionare (CRQ), respectivamente, após o programa de treinamento de resistência supervisionado, e, em seguida, os pacientes foram divididos em dois grupos: tratamento domiciliar ( $n=$ $10)$ e controle $(n=12)$. Após 16 semanas, as avaliações foram repetidas. Resultados: $O$ treinamento resistido em domicílio não mostrou aumento significativo sobre a força muscular periférica e qualidade de vida, no entanto, foi capaz de manter os ganhos obtidos após o programa de treinamento supervisionado. Conclusão: A continuidade do tratamento em domicílio não promoveu melhorias adicionais após o protocolo, uma vez que os ganhos foram mantidos nos dois grupos avaliados após 4 meses.
\end{abstract}

Palavras-chave: DPOC. Tratamento Domiciliar. Treinamento de Resistência. Qualidade de Vida.

\begin{abstract}
Design of the study: clinical Trial. Objective: This study aimed to evaluate the effects of a homebased resistance exercise program with elastic tubing after supervised resistance training on peripheral muscle strength and quality of life in patients with chronic obstructive pulmonary disease (COPD). Methods: The study included 22 COPD patients, aged 55-70 years. Peripheral muscle strength and quality of life were evaluated through digital dynamometer and Chronic Respiratory Disease Questionnaire (CRDQ) respectively after supervised resistance training program, and then the patients were divided into two groups: home-based treatment $(n=10)$ and control $(n=12)$. After 16 weeks the assessments were repeated. Results: The home resistance training showed no significant increase in peripheral muscle strength and quality of life, however, was able to maintain the gains made in the previous supervised training. Conclusion: The continuity of home-based treatment did not promote additional improvements to supervised training after the protocol, since the gains were maintained in both assessed groups after 4 months.
\end{abstract}

Key words: COPD. Residential Treatment. Resistance Training. Quality of Life.

1. Discente do Departamento de Fisioterapia, Faculdade de Ciências e Tecnologia da Universidade Estadual Paulista (UNESP) Presidente Prudente, São Paulo, Brasil.

2. Professor Doutor do Departamento de Fisioterapia, Faculdade de Ciências e Tecnologia da Universidade Estadual Paulista (UNESP) Presidente Prudente, São Paulo, Brasil.
Corresponding: Giovana Navarro Bertolini Physiotherapy Department, São Paulo State University Roberto Simonsen, n0305 CEP: 19060-900, Presidente Prudente, São Paulo, Brazil

Recebido em 17/04/2015 Aprovado em 10/12/2015 


\section{Introduction}

Chronic obstructive pulmonary disease (COPD) is a preventable and treatable disease with significant systemic effects which contributes to the severity of symptoms. ${ }^{1}$ The disease affects $85 \%$ of smokers aged over 40 years and is estimated to be the third leading cause of death worldwide by 2020. ${ }^{1}$ The management of COPD involves drug therapy, smoking cessation, and participation in pulmonary rehabilitation programs. ${ }^{2}$

Pulmonary rehabilitation is widely recommended for patients with COPD and aims to improve peripheral muscle strength and quality of life. ${ }^{3}$ However, not all patients adhere to rehabilitation programs. Travel and transportation are often cited as barriers to achieving center-based programs. Other models of pulmonary rehabilitation, including home-based programs, have been proposed to improve access in the treatment to COPD patients. ${ }^{4,1}$

A major component of pulmonary rehabilitation is exercise. Among its modalities, resistance training proves to be able to improve functional performance, quality of life, reduce sensitivity to dyspnea and reverse, partially, peripheral muscle dysfunction in COPD. 5,6,7

However, these benefits begin to decrease after 30 days of discontinuing rehabilitation program. ${ }^{8,9}$ Thereby; home-based training programs have been proposed for the maintenance of gains after conclusion of supervised rehabilitation programs. ${ }^{10,11,12}$

It is known that the equipment commonly used to practice resistance training require large physical space, are difficult to move, and present a high cost, which difficult its acquisition in a home environment. Thus, the elastic tubing appears as an additional alternative, presenting a viable treatment for these patients 13,14 and has proved to be a safety feature, easy to manipulate and inexpensive. ${ }^{15}$ Despite these advantages, not much is known about the effects of this tool in a home-based resistance program in patients with COPD.

Therefore, this study aimed to evaluate the effects of a home-based resistance exercises program with elastic tubing, after supervised training on peripheral muscle strength and quality of life in patients with COPD.

\section{Methods}

\section{Participants}

The sample consisted of volunteers in primary, sent both the public system and the private system to the Study Centre and Service in Physical Therapy and Rehabilitation, Faculty of Science and Technology - FCT / UNESP - Presidente Prudente campus.

The recruited subjects participated in another original study of pulmonary rehabilitation, whose exclusion criteria were: not to be in smoking abstinence for at least a year, presence of disabling and / or unstable heart disease that could influence the performance of physical activity, exacerbations or changes in medication in the last 30 days and use of home oxygen therapy.

The study evaluated the effect of a 16 weeks home-based program after supervised resistance training on peripheral muscle strength and quality of life of 22 patients diagnosed with COPD according to the criteria established by the Global Initiative for Obstructive Lung. Disease. ${ }^{1}$

Patients were informed about all the procedures and objectives of the study and, after agreeing, signed a consent form. All procedures used in this study were approved by the Institutional Ethics Committee (Protocol: 104/2010). Universal Trial Number: U1111-1159-7179.

\section{Experimental Design}

At the end of a supervised resistance, training program ${ }^{13}$ patients were invited to continue their resistance training with elastic tubing at home for 16 weeks. Patients who chose willingly to continuing treatment in the home environment made up the home-based treatment group and those who did not want to continue agreed to participate of the evaluations proposed thus composing the control group.

The study was conducted from July to October 2013 and the experimental protocol consisted of an evaluation performed at baseline and after 16 weeks of home-based resistance training. We performed anthropometric evaluation, pulmonary function assessment by spirometry, peripheral muscle strength by dynamometry and quality of life through the Chronic Respiratory Disease Questionnaire (CRDQ). 
In patients in home-based training group, the fatigue resistance test with elastic tubing was performed to determine the initial training load. This test was repeated every 4 weeks for load increase. The control group was instructed not to perform any type of physical activity during the 16 weeks.

\section{Pulmonary Function}

For the evaluation of Lung. function, spirometry was performed using spirometer MIR-Spirobank version 3.6 coupled to a microcomputer. The data interpretation was in accordance with the standards of the American Thoracic Society and European Respiratory Society. ${ }^{16}$ The normality values were considered to the Brazilian population. ${ }^{17}$

\section{Resistance to fatigue test}

The determination of the training load through the fatigue resistance test was obtained from the higher number of repetitions of each performed movement (knee extension and knee flexion, shoulder abduction and shoulder flexion), until it was reached muscle fatigue. The number of repetitions and the time were timed (40-60 seconds) until the patient reached exhaustion. This was used as a reference value to obtain the number of repeats proportionate to 20 seconds. This is the time which the adenosine triphosphate-creatine phosphate (ATPCP) system is consumed by muscle cells for energy. ${ }^{18}$

Latex elastic ropes tube-type was used for test execution. It was standardized thickness of two millimeters for upper limbs and four millimeters to lower limbs. The test was considered ideal when the reported fatigue was at the time of $45 \pm 5$ seconds. From the results obtained in the fatigue resistance test, we determined the number of sets and repetitions for each specific muscle group trained. ${ }^{13}$

\section{Home-based Resistance Exercise Protocol}

After the initial assessments, we conducted home visits for the training group aiming to adapt the place for the exercises. Besides, a book of guidance and control of physical activity was provided to the patients. Also we weekly contacted the patients through phone to control the routine of exercises and their general health.

During the 16-week treatment, home-based group performed a resistance exercise protocol with elastic tubing (Lemgruber $\AA$ brand, Brazil), with a frequency of three times a week, without direct supervision. The patients were previously informed about the correct way to perform each one of the exercises. The following movements were executed: knee flexion, knee extension, shoulder flexion and shoulder abduction.

The prescription of repetitions and the determination of the exercise load were based on resistance of fatigue test with elastic tubing, performed individually and specific to each movement. The protocol started with 2 sets and the load was progressively increased by adding one more set every two sessions, ending with 7 sets, completing 4 weeks of training. Then, a new fatigue resistance test was performed and carried out a new prescription. The new prescription was always performed after the end of 4 weeks of training. ${ }^{13}$

\section{Quality of life}

To assess quality of life, the Chronic Respiratory Disease Questionnaire (CRDQ) was applied. ${ }^{19}$ The questionnaire contains 20 questions divided into four domains: dyspnea (5 questions), fatigue (4 questions), emotional function (7 questions) and illness control (4 questions). The questionnaire was administered by a single interviewer in all periods. The evaluation was performed at baseline, after completion of the supervised program and after four months of home monitoring.

\section{Measurement of peripheral muscle strength}

The measurement of peripheral muscle strength was performed unilaterally (dominant limb) through digital dynamometer Force Gauge ${ }^{\circledR}$ brand, model FG-100 kg. The results were expressed in Newtons. The patient was instructed to perform the movement (knee extension, knee flexion, shoulder flexion and shoulder abduction) against the resistance of a steel cable attached to the dynamometer. The patient underwent his maximal voluntary isometric contraction (MVIC) for 6 seconds, followed by relaxation of the limb. The measurement was repeated three times, with an interval of 1 minute between them, and the highest value was recorded. ${ }^{20}$

\section{Statistical Analysis}

Data analysis was performed in GraphPad Prism $\AA$ software. The normality of data was per- 
formed by the Shapiro-Wilk test. For comparison between the initial moments and after 16 weeks in each group Student's t paired test was performed for parametric distributions or Wilcoxon test for nonparametric distributions. A comparison of the baseline stages and 16 weeks between the groups (treatment and control) was performed by Student $t$ test for parametric distributions or Mann Whitney test for nonparametric distributions. Data were expressed as mean and standard deviation, and the level of significance was $p<0.05$.

\section{Results}

Twenty-two patients were included in the study, divided into two groups: Home-based exercise Group: $n=10$ (Stage II: $n=2$, Stage III: $\mathrm{n}=.8$ ), and control group: $\mathrm{n}=12$ (Stage II: $\mathrm{n}=6$, Stage III: $n=4$, Stage IV: $n=2$.) Sixteen patients concluded the study. (Figure 1 ).

Table 1 demonstrates that there was no difference among the groups in relation to anthropometric and spirometric data.

Table 2 shows baseline values and after 16 weeks of training of peripheral muscle strength and CRDQ domains. No change during the protocol was observed in both groups.
Table 1. Anthropometric and spirometric data of patients with COPD.

\begin{tabular}{lc}
\hline Características & COPD Patients $(\mathrm{n}=16)$ \\
\hline Gender: M/F & $13 / 3$ \\
Age $($ years $)$ & $64,31 \pm 8,14$ \\
BMI $\left(\mathrm{kg} / \mathrm{m}^{2}\right)$ & $26,01 \pm 4,25$ \\
FEV $_{1} / \mathrm{FVC}$ & $48,63 \pm 12,33$ \\
FEV $_{1}$ (\%predicted) & $45,69 \pm 16,88$ \\
FVC (\%predicted) & $74,44 \pm 23,53$ \\
\hline
\end{tabular}

Data presented as mean and standard deviation. COPD $=$ chronic obstructive pulmonary disease; $\mathrm{M}=$ male; $\mathrm{f}=$ female; $\mathrm{BMI}=$ body mass index; $\mathrm{FEV}_{1} / \mathrm{FVC}=$ Tiffeneau Index; $\mathrm{FEV}_{1}=$ Forced expiratory volume in one second; FVC = forced vital capacity.

Table 3 shows the values of peripheral muscle strength and CRDQ domains after home-based training, which showed similar behavior. No significant differences were observed between groups.

\section{Discussion}

The study showed that during the 16 weeks of monitoring, the home-based exercise and control groups maintained the values obtained after a period of supervised training on peripheral muscle strength and quality of life.

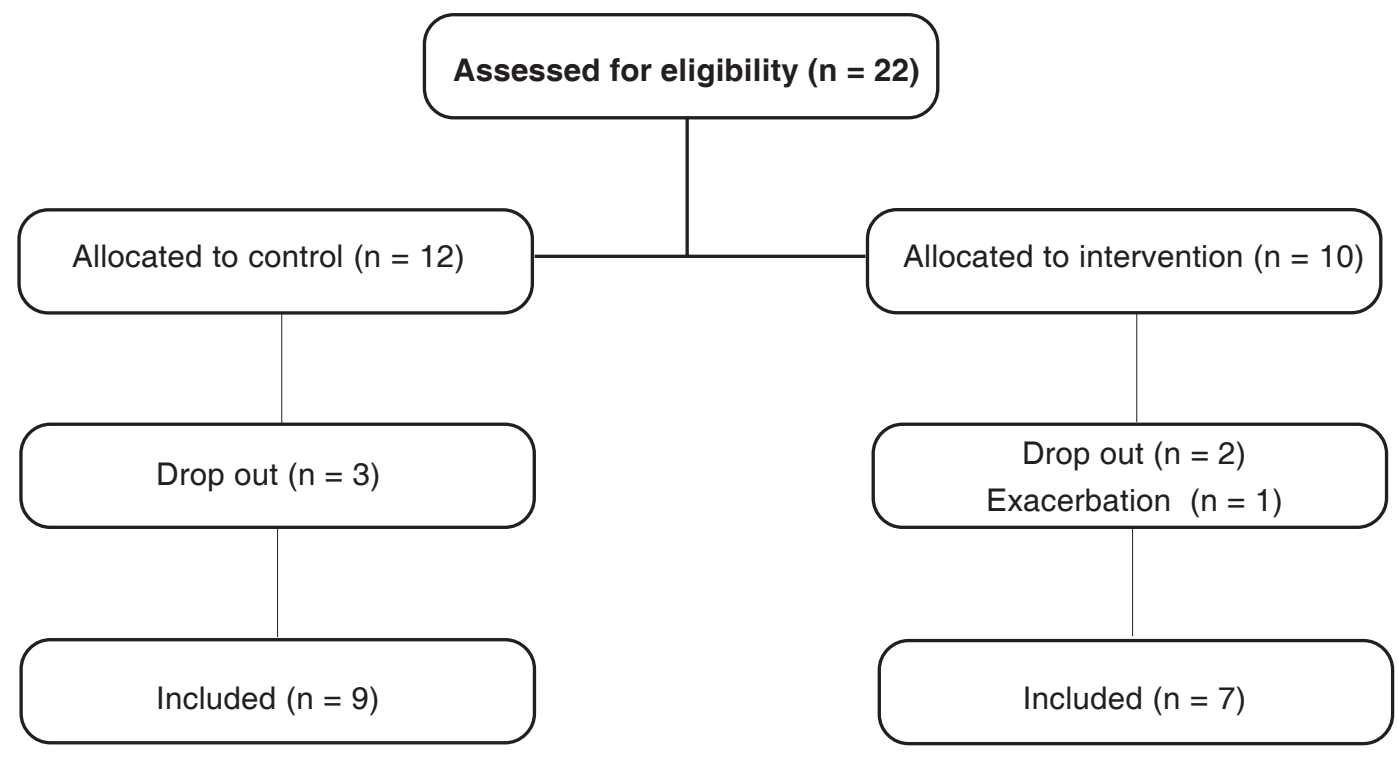

Figure 1. Flow diagram 
Table 2: Values of muscle strength and CRDQ domains of both groups before and after the home-based training.

\begin{tabular}{|c|c|c|c|c|c|c|}
\hline \multirow{3}{*}{$\begin{array}{l}\text { Variables } \\
\text { Muscle strength }\end{array}$} & \multicolumn{2}{|c|}{ Treatment Group } & \multirow{3}{*}{$p$ value } & \multicolumn{3}{|c|}{ Control Group } \\
\hline & \multicolumn{2}{|c|}{ No 7} & & \multicolumn{2}{|c|}{ No 9} & $p$ value \\
\hline & Baseline & 16 weeks & & Baseline & 16 weeks & \\
\hline Shoulder flexion (N) & $74,80 \pm 15,80$ & $74,34 \pm 21,88$ & 0,9348 & $76,49 \pm 22,60$ & $73,42 \pm 16,64$ & 0,5408 \\
\hline Shoulder Abduction (N) & $66,94 \pm 20,39$ & $67,94 \pm 17,71$ & 0,8436 & $63,73 \pm 19,09$ & $65,29 \pm 20,16$ & 0,8246 \\
\hline Knee extension ( $N$ ) & $246,7 \pm 72,86$ & $235,9 \pm 67,49$ & 0,2527 & $264,8 \pm 62,08$ & $255,0 \pm 84,15$ & 0,5852 \\
\hline Knee flexion (N) & $137,0 \pm 45,80$ & $145,8 \pm 45,64$ & 0,5781 & $127,9 \pm 23,48$ & $145,2 \pm 48,19$ & 0,1963 \\
\hline \multicolumn{7}{|l|}{ CRDQ Domains } \\
\hline Dyspnea & $4,286 \pm 1,336$ & $3,957 \pm 1,246$ & 0,5376 & $5,556 \pm 0,733$ & $5,022 \pm 1,573$ & 0,3281 \\
\hline Fatigue & $4,857 \pm 1,153$ & $4,083 \pm 1,143$ & 0,0522 & $5,361 \pm 1,257$ & $5,222 \pm 1,128$ & 0,5992 \\
\hline Emotional Function & $5,267 \pm 1,105$ & $5,166 \pm 1,467$ & 0,8014 & $5,462 \pm 1,011$ & $5,809 \pm 0,825$ & 0,2726 \\
\hline Illness Control & $5,750 \pm 1,061$ & $5,280 \pm 1,944$ & 0,4521 & $6,167 \pm 0,984$ & $6,361 \pm 0,697$ & 0,5721 \\
\hline
\end{tabular}

Data presented as mean and standard deviation. $\mathrm{N}=$ Newton.

Table 3: Comparation of values of muscle strength and CRDQ domains in both groups after home-based training.

\begin{tabular}{lccc} 
Variables & $\begin{array}{c}\text { Treatment Group } \\
\text { No } 7\end{array}$ & $\begin{array}{c}\text { Control Group } \\
\text { No } 9\end{array}$ & p value \\
Muscle strength & & & 0,9250 \\
Shoulder flexion (N) & $74,34 \pm 21,88$ & $73,42 \pm 16,64$ & 0,7873 \\
Shoulder Abduction (N) & $67,94 \pm 17,71$ & $65,29 \pm 20,16$ & 0,6321 \\
Knee extension (N) & $235,9 \pm 67,49$ & $255,0 \pm 84,15$ & 1,0000 \\
Knee flexion (N) & $145,8 \pm 45,64$ & $145,2 \pm 48,19$ & 0,1649 \\
& & & 0,0661 \\
CRDQ Domains & & & 0,2839 \\
Dyspnea & & $5,022 \pm 1,573$ & 0,3196 \\
Fatigue & $3,957 \pm 1,246$ & $5,222 \pm 1,128$ & $5,809 \pm 0,825$ \\
Emotional Function & $4,083 \pm 1,143$ & $6,361 \pm 0,697$ & \\
Illness Control & $5,166 \pm 1,467$ & $5,280 \pm 1,944$ & \\
\hline
\end{tabular}

Data presented as mean and standard deviation. $\mathrm{N}=$ Newton. 
Our results corroborate with the findings of O'Shea et al., (2007) that assessed COPD patients undergoing domiciliary resistance training with progressive load (elastic bands) for a period of 12 weeks, after a supervised training period and observed no significant differences in peripheral muscle strength and quality of life for these patients compared with the control group. ${ }^{15}$

Another study by Spencer et al., (2010) also showed maintenance of the gains on quality of life after a supervised rehabilitation program. In this study the home-based training was combined, 30 minutes of walking and 30 minutes of exercises for upper and lower limbs with free weights. The follow-up was for 12 months. ${ }^{21}$

On the other side, Brooks et al., (2002) showed a decline in CRDQ domains over 12 months for a home-based exercise program with monthly supervision. The study indicated that the frequency of supervision was insufficient to maintain the gains achieved after the supervised program. ${ }^{22}$

Moulin et al., (2009) found gains on quality of life, through CRDQ, during six months of treatment with aerobic exercises at home in patients with COPD who have previously participated in a supervised pulmonary rehabilitation program. ${ }^{23}$

Previous studies in patients with COPD that performed home-based intervention programs, demonstrated a variation in the frequency of supervision: once a week, 24,25 three times a week, 26 and once a month. 27,22 The frequency of supervision appears to be related to the results obtained in this mentioned studies.

Dodd et al., (2007) demonstrated that a home-based rehabilitation program for healthy elderly, showed lower results compared to center-based rehabilitation programs ${ }^{28}$, which may be a consequence of lack of supervision.

The impact of exercise training programs at home may be influenced by several factors, such as age, sex, socioeconomic status and anxiety. ${ }^{29}$

Another important factor demonstrated in the study of Brooks et al., (2002) was the decline in the number of patients in the course of home treatment. The purpose of the study was a 12 months follow-up, although it was observed a decrease in adherence, near half the patients dropped the program nine months after starting the treatment. ${ }^{22}$
In the present study we also observed a decrease in the number of patients who completed the homebased training, but these aspects were not the primary objective of this study.

Limitations of the study should be considered: First, the number of patients who completed the study protocol was relatively low. Second, we note the difficulty of adjusting the elastic tubing on conventional chairs found in patients homes, since in the supervised training the chair of the rehabilitation center were taller, which facilitated the execution of flexion and knee extension. This factor may have limited the performance of patients and difficult the achievement of better results.

In addition, we believe that no supervision of exercises in the household may have been a limiting factor in relation to patient compliance and therefore the results obtained. Considering that they had conducted a supervised training program, where we observed that patients trust the therapist and feel encouraged by the treatment group. So when made the proposal to continue at home without supervision we could observe accepted limitations on the continuation of the protocol.

Although gains in the evaluated periods were not evidenced in the home-based treatment, the proposed protocol has shown to be viable, safe and able to offer patients the ease and comfort of carrying out their treatment at home. Caring for adequacy for performing movements must be observed, as well as more frequent monitoring during the first days of the exercise protocol. The continuation of treatment, motivation, monitoring and supervision are critical aspects for patients after conclusion of a pulmonary rehabilitation program.

The study concluded that the continuity of home-based treatment, instructed but unsupervised, did not promote additional improvements to supervised training after the protocol, since the gains were maintained in both assessed groups after 4 months.

\section{Acknowledgements}

This work was supported by the following Brazilian Scientific Agencies: Fundação de Amparo à Pesquisa do Estado de São Paulo (FAPESP), Programa Institucional da Pró-Reitoria de Extensão - PROEX/UNESP and FUNDUNESP. 


\section{References}

1. GOLD. From the Global Strategy for the Diagnosis, Management and Prevention of COPD, Global Initiative for Chronic Obstructive Lung. Disease (GOLD) 2014. Available from: http://www.goldcopd.org/.

2. McKenzie D, Abramson M, Crockett A, et al. The COPD-X Plan: Australian and New Zealand Guidelines for the management of Chronic Obstructive Pulmonary Disease 2008. Australia Lung. Foundation/Thoracic Society of Australia and New Zealand. Available at: www.copdx.org.au/guidelines/ index.asp Last accessed: February 2009.

3. Maltais F, Decramer M, Casaburi R, Barreiro E, Burelle $Y$, Debigaré R, et. al. ATS/ERS Ad Hoc Committee on Limb Muscle Dysfunction in COPD. An official American Thoracic Society/European Respiratory Society statement: update on limb muscle dysfunction in chronic obstructive pulmonary disease. Am J Respir Crit Care Med. Med. 2014 May1; 189(9):e15-62.doi: 10.1164/rccm.201402-0373ST. Review

4. Holland AE, Mahal A, Hill CJ, Lee AL, Burge AT, Moore R, et.al. Benefits and costs of home-based pulmonary rehabilitation in chronic obstructive pulmonary disease - a multi-centre randomised controlled equivalence trial. BMC Pulm Med. 2013; 13:57.

5. O'Shea SD, Taylor NF, Paratz JD. Progressive resistance exercise improves muscle strength and may improve elements of performance of daily activities for people with COPD: a systematic review. Chest. 2009; 136: 1269-83.

6. Troosters T, Gosselink R, Janssens W, Decramer M. Exercise training and pulmonary rehabilitation: new insights and remaining challenges. Eur Respir Rev. 2010; 19:24-9.

7. Ortega F, Toral J, Cejudo P, Villagomez R, Sánches H, Castillo $\mathrm{J}$, et al. Comparasion of effects of strength and endurance training in patients with chronic obstructive pulmonary disease. Am J Respir Crit Care Med. Med. 2002; 166: 669-74.

8. Karapolat H, Atasever A, Atamaz F, Kirazli Y, Elmas F, Erdinç E. Do the benefits Gained Using a Short-Term Pulmonary Rehabilitation Program Remain in COPD Patients After Participation? Lung. 2007; 185: 221-5.

9. Cambach W, Wagenaar RC, Koelman TW, Van Keimpema AR, Kemper HC. The long-term effects of pulmonary rehabilitation in patients with asthma and chronic obstructive pulmonary disease: a research synthesis. Arch Phys Med Rehabil. 1999; 80: 103-11.

10. Spencer LM, Alison JA, McKeough ZJ. Maintaining benefits following pulmonary rehabilitation: a randomised controlled trial. Eur Respir J. 2010; 35:571-7.

11. Wijkstra PJ, TenVergert EM, Altena RV, Kraam J, Postma DS, Koeter GH. Long term benefits of rehabilitation at home on quality of life and exercise tolerance in patients with chronic obstructive pulmonary disease. Thórax. 1995; 50:824-8.

12. Berry MJ, Rejeski WJ, Adair NE, Ettinger WH Jr, Zaccaro DJ, Sevick MA. A randomized, controlled trial comparing long-term and short-term exercise in patients with chronic obstructive pulmonary disease. J Cardiopulm Rehabil. 2003; 23: 60-8.

13. Ramos EMC, de Toledo-Arruda AC, Fosco LC, Bonfim R, Bertolini GN, Guarnier FA, et al. The effects of elastic tubingbased resistance training compared with conventional resistance training in patients with moderate chronic obstructive pulmonary disease: a randomized clinical trial. Clin Rehabil. 2014; 28:1096-106.
14. Silva EG, Dourado VZ. Treinamento de forca para pacientes com doença pulmonar obstrutiva crônica. Rev Bras Med Esporte. 2008; 14: 231-8.

15. O'Shea SD, Taylor NF, Paratz JD. A predominantly homebased progressive resistence exercise program increases knee extensor strength in the short-term in people with chronic obstructive pulmonary disease: a randomized controlled trial. Aust J Physiother. 2007; 53:229-37.

16. Miller MR, Hankinson J, Brusasco V, Burgos F, Casaburi R, Coates A, et al. Standardization of spirometry. Eur Respir J. 2005; 26:319-38.

17. Neder JA, Andreoni S, Castelo-filho A, Nery LE. Reference values for Lung. function tests. I. Static volumes. Braz J Med Biol Res. 1999; 32:703-17.

18. Jürgen Weineck. Biologia do Esporte; tradução por Anita Viviani; Parte III: Sistemas Orgânicos e Treinamento Esportivo. São Paulo: Manole, 2000. p. 37-42.

19. Guyatt GH, Berman LB, Townsend M, et al. A measure of quality of life for clinical trials in chronic Lung. disease. Thórax. 1987; 47:773-8.

20. O'Shea SD, Taylor NF, Paratz JD. Obstructive Pulmonary Disease: Retest Reliability of Hand-Held Dynamometry. Arch Phys Med Rehabil. 2007; 88: 32-6.

21. Spencer LM, Alison JA, McKeough ZJ. Maintaining benefits following pulmonary rehabilitation: a randomized controlled trial. Eur Respir J. 2010; 35:571-7.

22. Brooks D, Krip B, Mangovski-Alzamora S, Goldstein RS. The effect of post rehabilitation programmes among individuals with chronic obstructive pulmonary disease. Eur Respir J. 2002; 20: 20-9.

23. Du Moulin M; Taube K, Wegscheider K, Behnke M, Vanden Bussche $\mathrm{H}$. Home-Based Exercise Training as Maintenance after Outpatient Pulmonary Rehabilitation. Respiration. 2009; 77:139-45.

24. Guell R, Casan P, Belda J, Sangenis M, Morante F, Guyatt $\mathrm{GH}$, et al. Long-term effects of outpatient rehabilitation on COPD. Chest. 2000; 117: 976-83.

25. Moullec G, Ninot G, Varray A, Desplan J, Hayot M, Prefaut C. An innovative maintenance follow-up program after a first inpatient pulmonary rehabilitation. Respir Med. 2008; 102: 556-66.

26. Berry MJ, Rejeski WJ, Adair NE, Ettinger WH Jr, Zaccaro DJ, Sevick MA. A randomized, controlled trial comparing long-term and short-term exercise in patients with chronic obstructive pulmonary disease. J Cardiopulm Rehabil. 2003; 23: 60-8.

27. Ries AL, Kaplan RM , Myers R , Prewitt LM . Maintenance after pulmonary rehabilitation in chronic Lung. disease. Am J Respir Crit Care Med. 2003; 167: 880-8.

28. O'Shea SD, Taylor NF, Paratz JD. A predominantly homebased progressive resistence exercise program increases knee extensor strength in the short-term in people with chronic obstructive pulmonary disease: a randomized controlled trial Aust J Physiother. 2007; 53:229-37.

29. Ferri M, Brooks D, Goldstein RS. Do our patients do what we ask of them? The what, why and how of compliance to treatment. Physiother Can. 1998; 50:286-90. 